\title{
Influence of the track quality and of the properties of the wheel rail rolling contact on vehicle dynamics
}

\author{
B. Suarez, J. Felez, J. A. Lozano and P. Rodriguez
}

This work describes an analytical approach to determine what degree of accuracy is required in the definition of the rail vehicle models used for dynamic simulations. This way it would be possible to know in advance how the results of simulations may be altered due to the existence of errors in the creation of rolling stock models, whilst also identifying their critical parameters. This would make it possible to maximize the time available to enhance dynamic analysis and focus efforts on factors that are strictly necessary.In particular, the parameters related both to the track quality and to the rolling contact were considered in this study. With this aim, a sensitivity analysis was performed to assess their influence on the vehicle dynamic behaviour. To do this, 72 dynamic simulations were performed modifying, one at a time, the track quality, the wheel-rail friction coefficient and the equivalent conicity of both new and worn wheels. Three values were assigned to each parameter, and two wear states were considered for each type of wheel, one for new wheels and another one for reprofiled wheels.After processing the results of these simulations, it was concluded that all the parameters considered show very high influence, though the friction coefficient shows the highest influence. Therefore, it is recommended to undertake any future simulation job with measured track geometry and track irregularities, measured wheel profiles and normative values of wheel-rail friction coefficient.

This is an electronic version of an article published in Vehicle System Dynamics, Vol. 51, No. 2, 2013, pp. 301-320.

VEHICLE SYSTEM DYNAMICS is available online at:

http://www.tandfonline.com/doi/abs/10.1080/00423114.2012.725853

DOI: $10.1080 / 00423114.2012 .725853$

When citing this work, please refer to the published paper:

B. Suarez, J. Felez, J. A. Lozano and P. Rodriguez, Influence of the track quality and of the properties of the wheel rail rolling contact on vehicle dynamics. Vehicle System Dynamics, Vol. 51, pp. 301-320. 


\title{
Influence of the track quality and of the properties of the wheel-rail rolling contact on vehicle dynamics
}

\author{
Berta Suarez ${ }^{1}$, Jesus Felez, Jose Antonio Lozano, Pablo Rodriguez \\ Universidad Politécnica de Madrid. CITEF (Research Centre on Railway Technologies) \\ ETSI Industriales (CITEF), C/ Jose Gutierrez Abascal, 2, ES-28006 Madrid, SPAIN
}

\begin{abstract}
This work describes an analytical approach to determine what degree of accuracy is required in the definition of the rail vehicle models used for dynamic simulations. This way it would be possible to know in advance how the results of simulations may be altered due to the existence of errors in the creation of rolling stock models, whilst also identifying their critical parameters. This would make it possible to maximize the time available to enhance dynamic analysis and focus efforts on factors that are strictly necessary.

In particular, the parameters related both to the track quality and to the rolling contact were considered in this study. With this aim, a sensitivity analysis was performed to assess their influence on the vehicle dynamic behaviour. To do this, 72 dynamic simulations were performed modifying, one at a time, the track quality, the wheel-rail friction coefficient and the equivalent conicity of both new and worn wheels. Three values were assigned to each parameter, and two wear states were considered for each type of wheel, one for new wheels and another one for reprofiled wheels.

After processing the results of these simulations, it was concluded that all the parameters considered show very high influence, though the friction coefficient shows the highest influence. Therefore, it is recommended to undertake any future simulation job with measured track geometry and track irregularities, measured wheel profiles and normative values of wheel-rail friction coefficient.
\end{abstract}

Keywords: railway dynamics, sensitivity analysis, dynamic behaviour, track quality, wheelrail friction coefficient, equivalent conicity, worn wheels, safety, track fatigue, ride quality, EN 14363 standard, UIC 518 leaflet

\section{INTRODUCTION}

The use of mathematical models to study the track-vehicle interaction is a common engineering practice nowadays, both as an aid in the design process or even as a tool to analyze its dynamic behaviour. To this end, reliable models of the systems to be analyzed are needed. Unfortunately, the actual values of some parameters that affect the system dynamics are sometimes unknown, which can lead to unreliable predictions.

This work proposes an analytical approach to determine what degree of accuracy is required in the definition of certain parameters in new models used for dynamic simulations. This way it would be possible to know in advance how the results of simulations may be altered due to the existence of errors in the creation of rolling stock models, whilst also identifying their critical parameters. This would make it possible to maximize the time available to enhance dynamic analysis and focus efforts on factors that are strictly

\footnotetext{
${ }^{1}$ Corresponding author: Berta Suarez, e-mail: citef-bsuarez@etsii.upm.es,

Postal address: ETSI Industriales (CITEF), C/Jose Gutierrez Abascal, 2, ES-28006 Madrid, SPAIN
} 
necessary. Furthermore, an improved reliability of the simulation results may found implications in the design of rolling stock, in making decisions to purchase new equipment, in the definition of track layouts, in assessing the risk of component failure in vehicles or infrastructure and, particularly, in the reconstruction of accidents.

In particular, it was intended to analyze the influence of some parameters which are directly related to the wheel-rail rolling contact, as the track quality, the wheel-rail friction coefficient and the equivalent conicity. This study is part of a wider work (1), and is complemented with two others, where the sensitivity of the inertial properties of the main bodies of the vehicle (2), as well as that of the elastic properties of vehicle suspensions were also analyzed (3).

To consider the influence of the model uncertainties on the vehicle dynamics, a probabilistic approach should be used, as it would predict how the uncertainty of input parameters would be propagated to the model output. A probabilistic method commonly used in such situations is the Monte Carlo simulation, but it requires extremely high computation costs when many uncertain input parameters have to be considered. Other more effective probabilistic methods are sometimes used as, for example, the combination of Monte Carlo simulation technique and the design of experiments theory (4) or the generalized polynomial chaos theory (5), though they are also time consuming.

Despite their high computational cost, probabilistic methods should be used whenever quantitative results are required. However, for preliminary research studies, where qualitative results showing the relative importance of the parameters being considered would suffice, simpler methods could be applied. The simplest method consists in modifying input parameters one at a time, thus neglecting any possible relationship that could exist between them. These simplifications make the precision of this method lower than the precision of the previously mentioned probabilistic methods. However, it is very helpful due to its simplicity, which allows analyzing many parameters with a relatively low computational cost, in comparison with the probabilistic methods.

As stated before, the work here exposed is part of a wider study, where the influences of 24 input parameters of the vehicle model were considered: 12 inertial properties of the vehicle bodies, 8 elastic properties of the suspension components and 4 parameters related with the rolling contact. For each parameter, several track layouts and vehicle speeds were also considered. The problem concerning the assessment of the influence of all these vehicle input parameters was considered as a whole, and the same approach was used for all of them, even though the problem related to the properties of the rolling contact, here exposed, is highly non-linear, much more than the problems related to suspension or inertial parameters. Due to the large number of uncertain input parameters and external conditions to be considered, and having in mind the above mentioned considerations, the simplest approach was chosen for this study. Therefore, the input parameters were modified one at a time, with just three values in each variation, so assuming that the output quantities are smooth functions of the input parameters.

In view of the above mentioned limiting conditions, the present work could be considered as a starting point, as it would provide a qualitative idea about which influence quantities need to be addressed with particular care when performing simulations addressing a specific problem. From the results obtained, the number of parameters to be considered to undertake in the future a probabilistic approach could be reduced. This way, quantitative and more accurate results could be obtained with a considerable lower computational cost than considering all the uncertain input parameters.

To undertake this work, a reference vehicle model was defined (6), (7). From this reference model, the values of the properties of the wheel-rail rolling contact to be analyzed were independently modified, one at a time. Three different track qualities were considered 
in this study. In the same way, in order to consider different values of the equivalent conicity, several wheel profiles were also included in the simulation models. These wheel profiles were chosen so that the equivalent conicities obtained for lateral displacements of the wheels of $3 \mathrm{~mm}$ would substantially differ from one wheel profile to another. For each wheel, two wear states were also considered, one for a new wheel and another one for a reprofiled wheel.

A methodology was also developed, to allow a systematic analysis of vehicle dynamic response, thus avoiding to focus on extremely specific cases. With this aim, entirely generic simulation scenarios were defined. In the same way, systematic statistical treatment was carried out on the simulation results. To define the track layouts and the track qualities to be used in the simulations, the specifications stated in the UIC-518 leaflet (8) and in the European standard EN-14363 (9), generally used for railway vehicle authorisation by means of on-track tests, were applied in a virtual environment. The same specifications were also used to post-process the results of the simulations. This procedure was chosen for this project because it is well established, supported by many years of experience, and allows the assessment of vehicle dynamics by means of only a few indexes. These indexes can be compared with some limit values, defined in these standards, in order to find whether the vehicle behaviour is suitable or not from a safety, track fatigue and ride quality point of view.

This methodology allows the identification of the critical parameters of the simulation models. It also allowed the identification of those properties of the wheel-rail rolling contact which could be estimated with a lesser degree of accuracy without appreciably affecting the accuracy of the simulation results, despite the fact that track defects and wheel wear are not commonly included in the models used to simulate vehicle-track interaction.

\section{BACKGROUND}

Though track quality is a factor which directly affects the vehicle dynamics, it is sometimes difficult to obtain measured data describing track irregularities.

Various publications presenting the results of several dynamic simulations in which the track quality was modified, dealing with safety studies can be found in: (10), (11), (12), (13), (14), (15), (16), (17) and (18); some others dealing with track fatigue studies can be found in: (11), (15), (16), (17), (18), (19), (20) and (21); and some dealing with ride quality studies in: (11), (15), (16), (17), (18), (22), (23), (24), (25) and (26).

This study intends to extend the scope of the previous works, trying to cover a range of track qualities wide enough to consider many of the possible values that could be found in different railway tracks.

In the same way, various publications presenting the results of several dynamic simulations in which the value of some parameters related to the wheel-rail contact, dealing with safety studies can be found in: (27), (28), (29), (30), (31), (32), (33), (34), (35), (36), (37), (38), (39), (40), (41), (42), (43), (44), (45), (46), (47), (48), (49), (50), (51), (52), (53), (54) and (55); some others dealing with track fatigue studies can be found in: (51), (52), (56) and (57); and some dealing with ride quality studies in: (58) and (59) .

As to the sensitivity analysis of the wheel-rail contact properties, the variations of the wheel-rail friction coefficient are usually related to derailment studies, while the variations of the equivalent conicity are usually related to stability studies, both linear and non-linear. In the latter studies, constant conicities are usually employed for linear stability, while the whole wheel profile is commonly considered for non-linear stability. 
This study intends to present a more comprehensive approach, trying to simultaneously analyze the influence of both the track quality and the properties of the rolling profiles in order to assess their impact on safety, track fatigue and ride quality, thus making it possible to determine which of these studies is more critical.

The same reference vehicle was employed to analyze the influence of all vehicle parameters considered in the above mentioned wider study: inertial properties, elastic properties and wheel-rail rolling properties. Three realistic track layouts were also used, with a cumulative length of $35 \mathrm{~km}$, covering a wide range of curve radii. In the same way, three different running speeds were considered for each track layout. Both the vehicle and track models are described in the next section.

In this way, it was intended to provide a wider view when analyzing the influence of both the track quality and the properties of the rolling profiles so as to assess their impact on vehicle dynamics.

\section{WORKING METHODOLOGY}

\subsection{SET-UP OF THE REFERENCE MODEL}

To perform the sensitivity analysis, multibody system (MBS) simulation techniques were employed. In particular, the SIMPACK commercial program was used. It allows simulating multi-body systems with especial features related with railway vehicle models, as the longitudinal guidance and the wheel-rail contact, which involves great forces transmitted through a small surface. SIMPACK has been tested in several benchmarks, as the Manchester benchmarks for railway vehicle dynamics (60), the ERRI Benchmark (61) or the Volpe LD benchmark (62).

The vehicle model represents a passenger car with two bogies, with the carbody resting on the elastic elements of the secondary suspension without any pivot or centre plate. The main bodies of the vehicle (carbody, bogie frames and wheelsets) were modeled as rigid bodies, connected to each other by means of linear springs and dampers that characterize the primary and secondary suspensions.

The vehicle model was parameterized with the aim of facilitating the variation of its features during the subsequent sensitivity analysis. Over 160 parameters were used. The vehicle model was built from smaller models of the individual components of the vehicle (carbody, bogie, primary suspension and secondary suspension). These sub-models are reusable and are assembled into the whole vehicle model. Numerical values were assigned to the different model parameters. These values were obtained from the median values of the data stored in the RVDynDB database, specifically made for this purpose (6), (7).

Three track models were also built, following the indications stated in the standard EN14363. These models include curves with large $(R>600 \mathrm{~m})$, medium $(400 \mathrm{~m} \leq R \leq 600 \mathrm{~m})$ and small $(250 \mathrm{~m} \leq \mathrm{R}<400 \mathrm{~m})$ radii, respectively called $R L, R M$ and $R S$. The specifications of this standard were also followed in the definition of track defects, specifically the alignment and longitudinal level, having chosen a track quality inside level QN1.

Vehicle and track models were coupled through the wheel-rail contact properties, defined by the Hertz theory for the normal forces, and by the Kalker's simplified theory for the tangential forces.

To consider the track elasticity in the model, track pieces were included under each wheelset. Each piece of track is directly supported by a pair of spring-damper elements.

The operating conditions were also set, following the specifications of the standard EN14363 , taking into account that the maximum operating speed of the reference vehicle was 
$160 \mathrm{~km} / \mathrm{h}$. Table 1 gathers the speeds used in the models for each of the three track layouts.

\begin{tabular}{|cccc|}
\hline $\begin{array}{c}\text { Track } \\
\text { layout }\end{array}$ & $\mathrm{R}_{\min }[\mathrm{m}]$ & $\mathrm{R}_{\max }[\mathrm{m}]$ & $\mathrm{V}_{\max }[\mathrm{km} / \mathrm{h}]$ \\
\hline $\mathbf{R L}$ & 1620 & 1950 & 175 \\
\hline $\mathbf{R M}$ & 570 & 600 & 105 \\
\hline $\mathbf{R S}$ & 290 & 375 & 75 \\
\hline
\end{tabular}

TABLE 1 CURVE RADII AND RUNNING SPEEDS

\subsection{INITIAL CONDITIONS FOR THE SENSITIVITY ANALYSIS}

In order to determine the velocity ranges to be used in the sensitivity analysis, the dynamics of the reference vehicle were simulated at several speeds, starting with a low speed and progressively increasing it. This way, the instability critical speed was identified for the track layout RL, as well as the minimum derailment speeds for each track model. The latter were associated with the lowest speed used in those simulations where it was detected that at least one wheel completely left the track, this indicating a derailment by excessive speed.

For the $R L$ track, the maximum speed, Vmax, was chosen just below the instability critical speed. The minimum speed, Vmin, was chosen so that the cant deficiency for the reference speed (Vref) would lie at the midpoint between the cant deficiencies for the extreme speeds Vmin and Vmax. The speed variation ranges for the track models RM and RS were defined so that they would have the same cant deficiency range as the first track model, RL. Table 2 shows the speed ranges so obtained for each track layout, together with their related cant deficiencies.

\begin{tabular}{|c|c|c|l|}
\hline $\begin{array}{c}\text { Track } \\
\text { layout }\end{array}$ & $\begin{array}{c}\text { Cant deficiency } \\
{[\mathrm{mm}]}\end{array}$ & $\begin{array}{c}\mathrm{V} \\
{[\mathrm{km} / \mathrm{h}]}\end{array}$ & \multicolumn{1}{|c|}{ Observations } \\
\hline \multirow{3}{*}{ RS } & 100 & 65 & Lower end \\
\hline \multirow{3}{*}{ RM } & 153 & 75 & Reference speed \\
\hline & 201 & 83 & Upper end \\
\hline \multirow{3}{*}{ RL } & 100 & 93 & Lower end \\
\hline & 148 & 105 & Reference speed \\
\hline & 202 & 117 & Upper end \\
\hline & 99 & 160 & Lower end \\
\hline & 134 & 175 & Reference speed \\
\hline \multirow{3}{*}{ TABLE 2 RUNNING SPEEDS FOR THE SENSITIVITY STUDY } \\
\hline
\end{tabular}

A more detailed description of the process followed to determine the speed ranges to be applied in the sensitivity study can be found in (6).

\subsection{DEFINITION OF SCENARIOS FOR THE SENSITIVITY ANALYSIS}

To perform the sensitivity analysis, the vehicle dynamics were simulated in different scenarios, which were built taking the vehicle reference model as starting point.

The first step in the definition of these scenarios was to modify independently, one at a time, the value of each of the parameters to be analyzed:

- Track quality (QN)

- Wheel-rail friction coefficient (f)

- Geometry of the wheel profile (wp) 


\subsubsection{Track quality}

To study the impact of the track quality, apart from the quality QN1, chosen as reference level, two other different track classes were considered, defined according to the indications of the EN-14363 standard: QN0, which is an ideal track with no defects, and QN2, with higher level of track defects than QN1. It should be pointed out that, obviously, a track with quality QNO falls out of the experimental conditions prescribed in the standard.

To define these track qualities, it is a common practice to use their respective power spectral densities, $\mathrm{S}(\Omega)$ being the spatial frequency, expressed in $\mathrm{rad} / \mathrm{m}$ :

$$
S(\Omega)=\frac{A \cdot \Omega_{C}^{2}}{\left(\Omega^{2}+\Omega_{R}^{2}\right) \cdot\left(\Omega^{2}+\Omega_{C}^{2}\right)}
$$

In this expression, the coefficients $A, \Omega_{\mathrm{R}}$ and $\Omega_{\mathrm{C}}$ should be experimentally obtained from real measurements of the track irregularities in a given track. In most of the references consulted (63), (16), (29), the values of $\Omega_{R}$ and $\Omega_{C}$ remain constant, and take the following values: $\Omega_{\mathrm{R}}=0.0206 \mathrm{rad} / \mathrm{m}$ and $\Omega_{\mathrm{C}}=0.8246 \mathrm{rad} / \mathrm{m}$.

For these same coefficients, the value of $A$, which is related to the amplitude of the track defects, was modified until track irregularities with the standard deviation stated in the EN14363 standard were reached. According to the indications of this standard, as each track model should be run at a different speed, the track irregularities of the $R L$ track layout should be treated separately from those of the RM and RS track layouts. Table 3 gathers the different values found for $A$.

\begin{tabular}{|c|r|r|r|}
\cline { 2 - 4 } \multicolumn{1}{c|}{} & Track & \multicolumn{2}{|c|}{ A coefficient [m.rad] } \\
\cline { 3 - 4 } & quality & Alignment & $\begin{array}{c}\text { Longitudinal } \\
\text { level }\end{array}$ \\
\hline \multirow{2}{*}{ RL model } & QN0 & 0 & 0 \\
\cline { 2 - 4 } & QN1 & $3.134 \cdot 10^{-7}$ & $7.284 \cdot 10^{-7}$ \\
\cline { 2 - 4 } & QN2 & $5.926 \cdot 10^{-7}$ & $13.137 \cdot 10^{-7}$ \\
\hline \multirow{2}{*}{$\begin{array}{c}\text { RM \& RS } \\
\text { models }\end{array}$} & QN0 & 0 & 0 \\
\cline { 2 - 4 } & QN1 & $7.403 \cdot 10^{-7}$ & $15.506 \cdot 10^{-7}$ \\
\cline { 2 - 4 } & QN2 & $11.568 \cdot 10^{-7}$ & $24.228 \cdot 10^{-7}$ \\
\hline
\end{tabular}

TABLE 3 POWER SPECTRAL DENSITY: COEFFICIENTS

Figure 1 shows a comparison between the standard deviations of the different levels of track irregularities introduced in the track models.

Standard devation of track irregularities

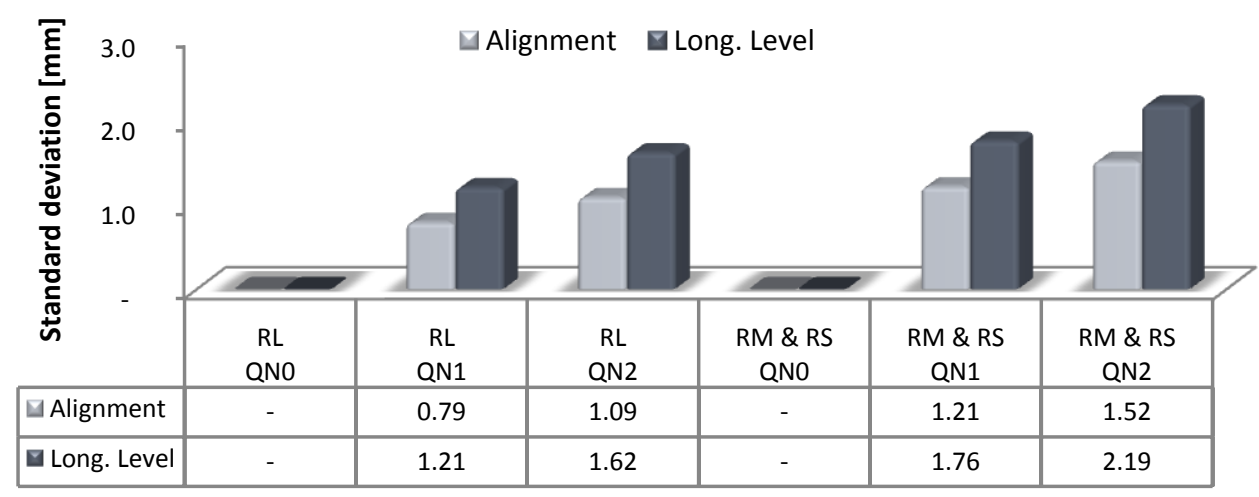

FIGURE 1 STANDARD DEVIATION OF TRACK DEFECTS 


\subsubsection{Wheel-rail friction}

As to the Wheel-rail friction coefficient, a reference value of 0.4 was used, and two additional values were considered apart from the reference value: a lower value and an upper value. These values were chosen so that they match with the extreme values commonly found for this parameter, which usually fall between 0.1 and 0.6.

\subsubsection{Wheel profiles}

In order to consider different values of the equivalent conicity, several wheel profiles were also defined, as well as different wear states. 9 different wheel profiles were initially considered, whose equivalent conicities (for lateral displacements of $\pm 3 \mathrm{~mm}$ ), in combination with a new UIC-60 rail profile, are shown in Table 4.

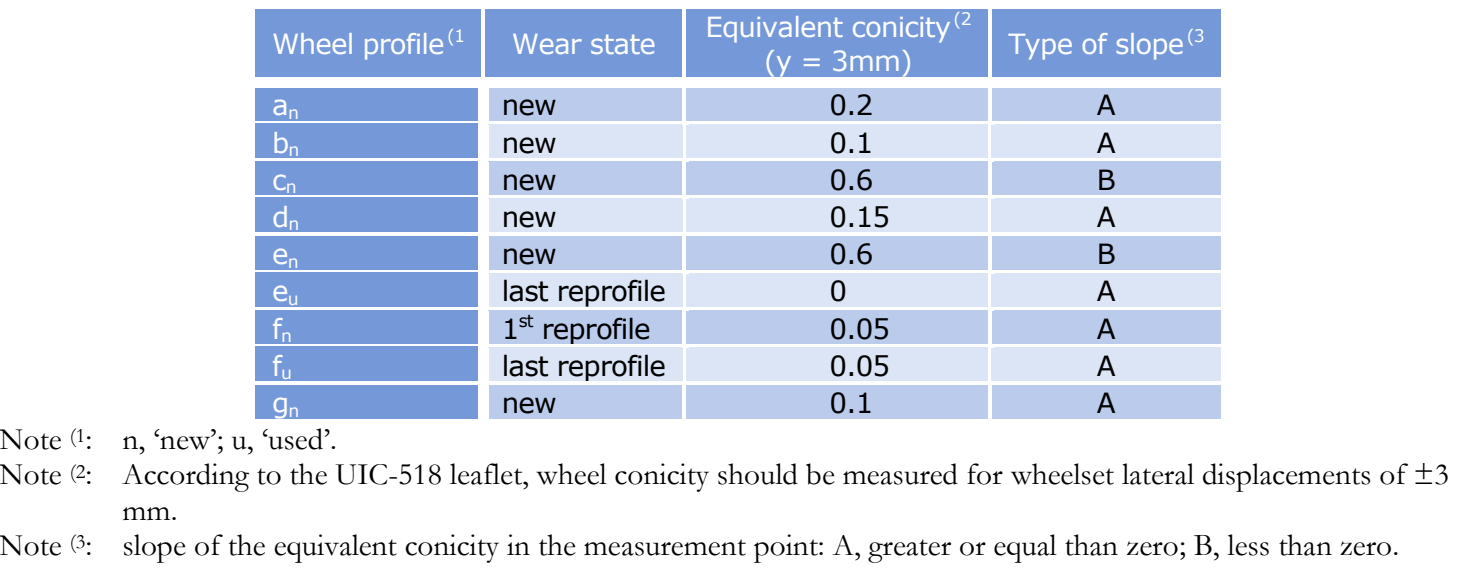

TABLE 4 EQUIVALENT CONICITY FOR LATERAL DISPLACEMENT OF 3 MM

The wheel profile used in the reference model is the $\mathrm{S} 1002\left(\mathrm{a}_{\mathrm{n}}\right.$ case), with an equivalent conicity of 0.2 . For further variations, two additional profiles were chosen. These other profiles were selected so that their equivalent conicities were respectively lower and higher than the reference one. In particular, the ' $f$ ' profile was chosen for low conicities, while the ' $e$ ' profile was preferred for high conicities. For new wheels, their conicities are respectively 0.05 and 0.6 . For both the reference profile, ' $a$ ', and the ' $f$ ' profile, the equivalent conicity have a slope greater than or equal to zero for lateral displacements of $\pm 3 \mathrm{~mm}$, while the ' $e$ ' profile has a negative slope (see Figure 2 ), which increase the interest of the sensitivity study (64). 


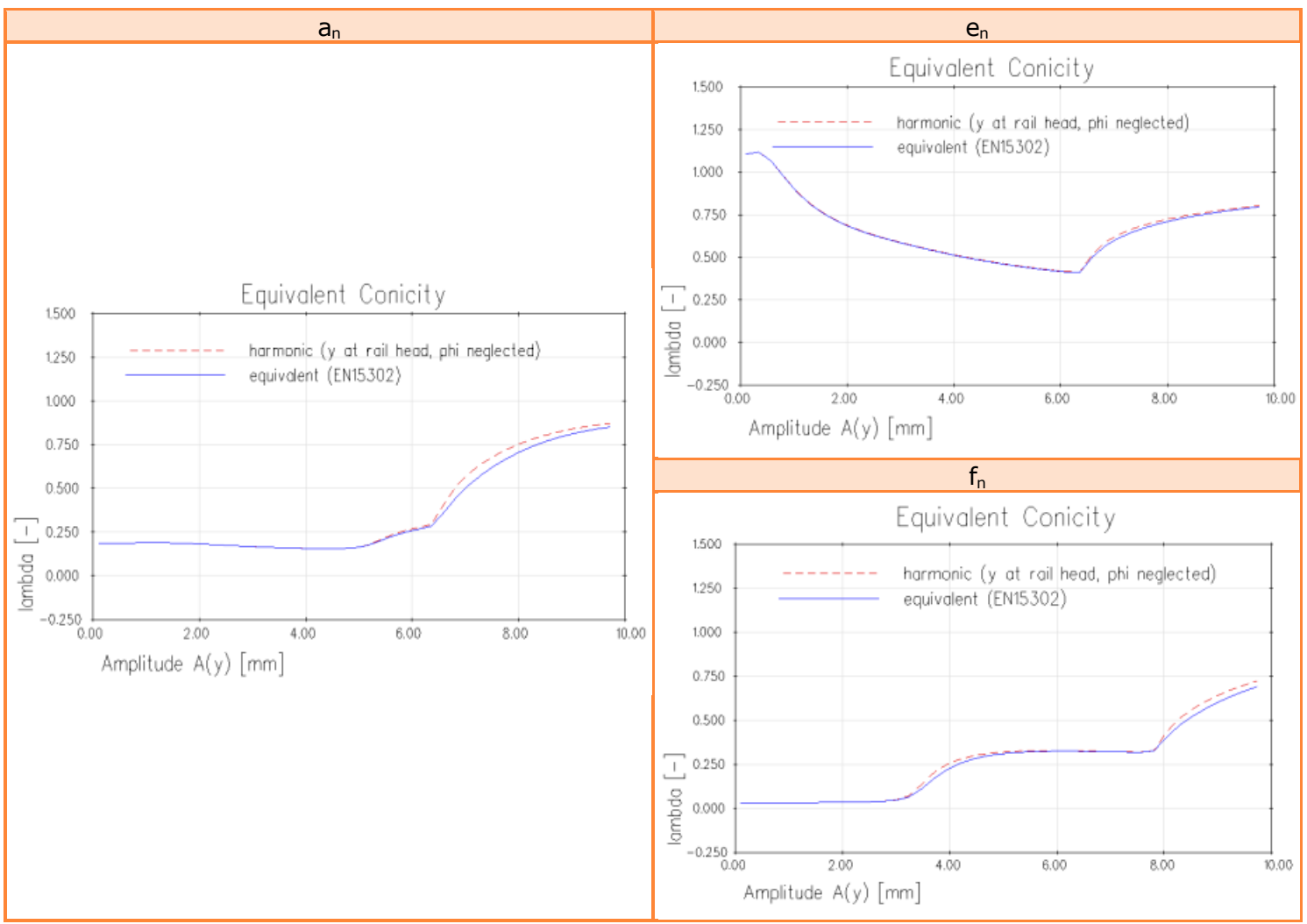

FIGURE 2 EQUIVALENT CONICITY VS. WHEEL DISPLACEMENT FOR LATERAL WHEEL DISPLACEMENTS UP TO 10 MM

In order to consider the effect of wheel wear on the vehicle dynamics, apart from the above mentioned new profiles, the 'e' and ' $f$ profiles were also included in the models with their maximum reprofiled state. In particular, the worn ' $f$ ' profile has an equivalent conicity of 0.05 and the 'e' profile has an equivalent conicity of 0 .

Figure 3 shows the reference profile, 'a', together with the 'e' profiles (left) and the ' $f$ ' profiles (right).
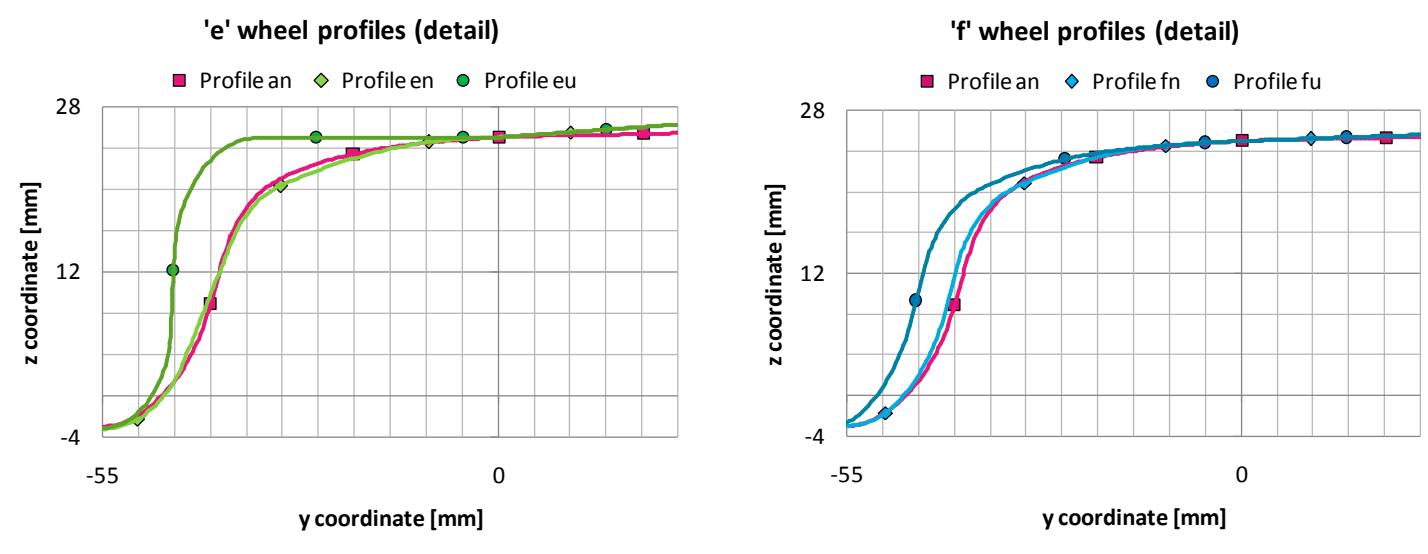

FIGURE 3 NEW AND USED WHEEL PROFILES

For each of these wheels, Figure 4 shows the position of the contact points for different lateral wheel displacements, when they are combined with a theoretic UIC-60 rail profile. 


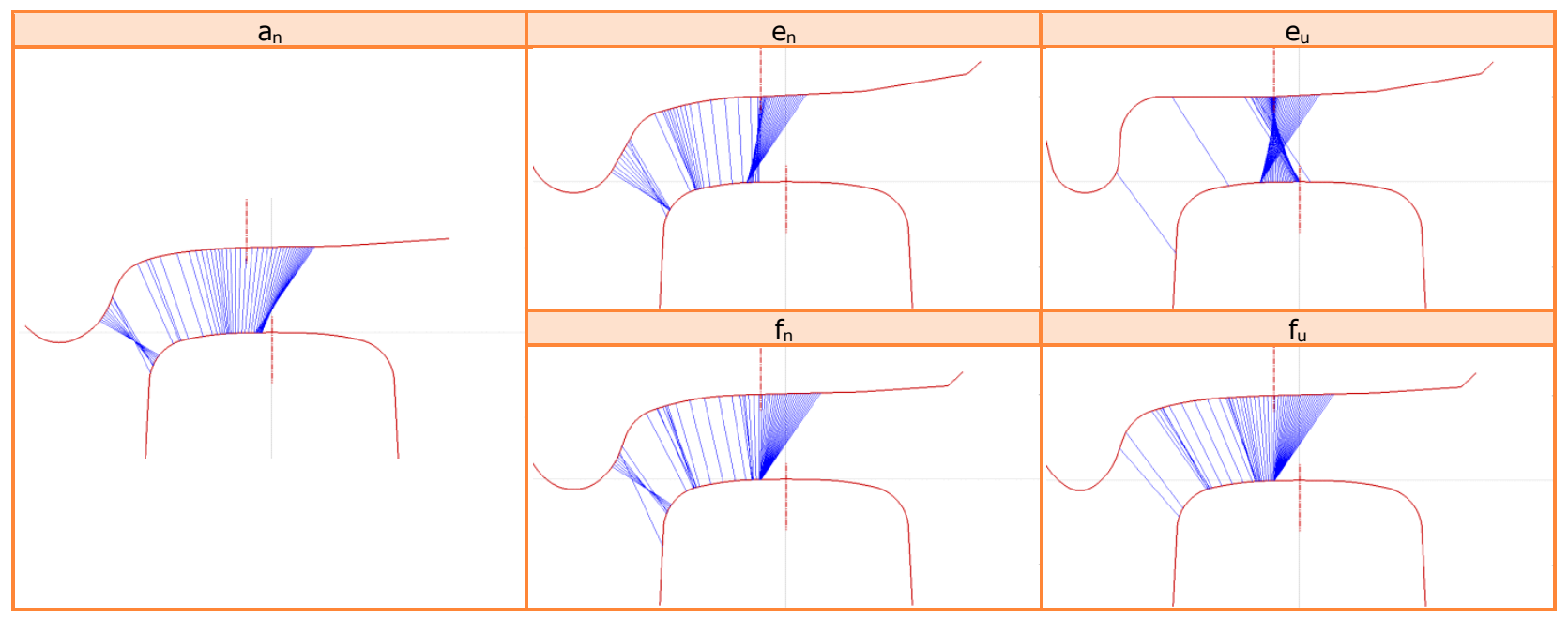

FIGURE 4 CONTACT POINT POSITIONS ON THE WHEEL AND RAIL PROFILES

From the visual comparison of the images depicted in Figure 4, it can be appreciated at a glance that the progression of the contact point is more uniform for the reference wheel profile (' $a_{n}$ ') than for the others, while the contact point shows a less uniform progression for the ' $e_{u}$ ' profile, which exhibits higher discontinuities that those found for other wheel profiles.

\subsubsection{Operating conditions}

Several operating conditions were considered for each of the values assigned to the previous parameters. In particular, each vehicle model was combined with the track layouts $\mathrm{RS}, \mathrm{RM}$ and RL. In turn, each track layout was run through at the running speeds Vmin, Vref and Vmax.

4 different scenarios were considered: 1 to analyze the influence of the track quality, 1 to analyze the wheel-rail friction coefficient, and 2 to analyze the equivalent conicity. Once the models were ready, they were simulated, with a total of 18 simulation ( 2 track qualities - 3 speeds $\cdot 3$ track layouts) to analyze the influence of the track quality, and 54 simulations ( 3 parameters $\cdot 2$ variations $\cdot 3$ speeds $\cdot 3$ track layouts) to analyze the properties of the wheelrail contact, apart from the 3 simulations performed to analyze the reference case,.

\subsection{Post-PROCESSING METHODOLOGY}

To make the comparison between the results of different simulations easier, the postprocessing methodology was systematized, reducing all the results of each simulation to a small set of indexes. To this end, the indications of the standard EN-14363 were followed. This standard proposes a statistical evaluation which allows the assessment of the vehicle dynamics from the safety, track fatigue and ride quality points of view.

As a whole, 5 assessment quantities were considered to evaluate running safety, 3 for track fatigue and another 5 for ride quality (Table 5). 


\begin{tabular}{|c|c|c|c|}
\hline & Index & Assessment quantity & Symbol \\
\hline \multirow{5}{*}{$\begin{array}{l}\stackrel{\overrightarrow{0}}{\mathbb{N}} \\
\text { ñ }\end{array}$} & SAF-1 & Sum of wheelset guiding forces & $(\Sigma \mathrm{Y})_{2 \mathrm{~m}}$ \\
\hline & SAF-2 & Ratio of guiding force and wheel load & $(\mathrm{Y} / \mathrm{Q})$ \\
\hline & SAF-3 & Lateral acceleration of the bogie frame & $\ddot{y}_{s}^{+}$ \\
\hline & SAF-4 & Lateral acceleration of the carbody & $\ddot{y}_{s}^{*}$ \\
\hline & SAF-5 & Root mean square of the sum of wheelset guiding forces & $s \Sigma Y$ \\
\hline \multirow{3}{*}{ 兽 } & FAT-1 & Vertical wheel load & $Q$ \\
\hline & FAT-2 & Quasi-static lateral wheel force & $Y_{q s t}$ \\
\hline & FAT-3 & Quasi-static vertical wheel force & $Q_{q s t}$ \\
\hline \multirow{5}{*}{$\begin{array}{l}\frac{z}{0} \\
\frac{0}{0} \\
\frac{0}{0} \\
\frac{0}{\alpha}\end{array}$} & COM-1 & Lateral acceleration of the carbody & $\ddot{y}_{q}^{*}$ \\
\hline & COM-2 & Vertical acceleration of the carbody & $\ddot{z}_{q}^{*}$ \\
\hline & COM-3 & Root mean square of lateral acceleration of the carbody & $s \ddot{y}_{q}^{*}$ \\
\hline & COM-4 & Root mean square of vertical acceleration of the carbody & $\mathrm{s} \ddot{z}_{q}^{*}$ \\
\hline & COM-5 & Quasi-static lateral acceleration of the carbody & $\ddot{y}_{q s t}^{*}$ \\
\hline
\end{tabular}

TABLE 5 ASSESSMENT QUANTITIES FOR SAFETY, TRACK FATIGUE AND RIDE QUALITY

The simulation results for each assessment quantity were post-processed following the indications of the standard EN-14363, in order to calculate their maximum estimated values.

The standard provides a limit value for each of the assessment quantities used to evaluate the vehicle dynamics, considering that the vehicle exhibits a suitable dynamic behaviour if the maximum estimated value for each assessment quantity is less than its related limit value.

\section{INDIVIDUAL RESULTS OF THE SENSITIVITY ANALYSIS}

After finishing the models and performing the appropriate simulations, the next step is to process the results obtained, following the indications of the standard EN-14363. The influence of a given parameter can then be determined by comparing each assessment index for all the simulations related to that parameter. These influences were independently evaluated for the different assessment quantities related to safety, track fatigue and ride quality studies.

\subsection{DESCRIPTION OF THE GRAPHICS AND TABLES USED}

\subsubsection{Result graphs}

When presenting the results, all the safety evaluation indexes (SAF) obtained when modifying a given parameter are grouped, as well as all the track fatigue (FAT) indexes and the ride quality $(\mathrm{COM})$ indexes.

To make comparisons easier, a $\lambda$ ratio is computed for each evaluation index. $\lambda$ represents the ratio between the maximum estimated value of the assessment quantity being analyzed, and its related limit value. It is expressed as a percentage, so that values under $100 \%$ represent standard-compliant situations, while those over $100 \%$ represent non-compliant ones.

A different graph was used for each evaluation criterion (SAF-1/5, FAT-1/3 or COM-1/5), and for each type of track section (curve, transition curve or straight track). In each graph, the results obtained in the simulations with track models $\mathrm{RS}$ (line with diamond-shape markers), RM (line with square markers) and RL (line with triangular markers) are shown together. 
The $y$-axis shows the $\lambda$ ratio, while the different scenarios used in the simulations are represented along the $x$-axis, by combining each running speed (Vmin/Vref/Vmax) with the three values assigned to the parameter being considered. As an example, Figure 5 shows the results obtained for the variations performed on the track quality, $\mathrm{QN}$, for the safety indexes SAF-1 and SAF-2, respectively related with the sum of guiding forces, $(\Sigma \mathrm{Y})_{2 \mathrm{~m}}$, and with the Nadal index, (Y/Q).

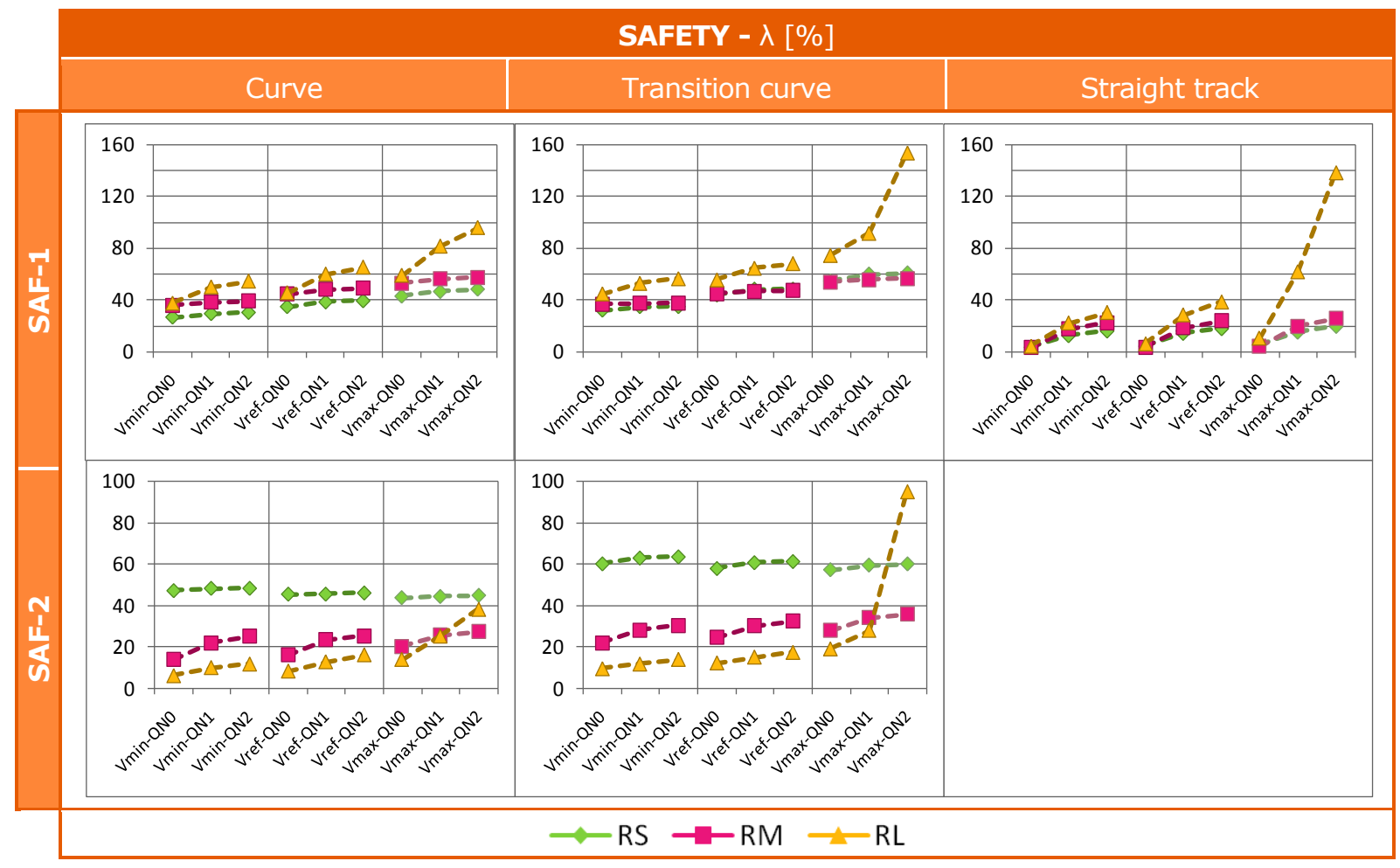

FIGURE 5 RESULTS OF THE VARIATIONS OF THE TRACK QUALITY: SAFETY

\subsubsection{Table of influences}

To assess the influence of the modified parameter, an influence indicator was computed, combining the $\lambda$ ratios obtained for either the maximum (Pmax) or minimum (Pmin) value and for the reference (Pref) value of the parameter being modified:

$$
I n f_{n}=\frac{\lambda_{n}-\lambda_{\text {ref }}}{(P n-P \text { ref }) / \text { Pref }}, \quad n=\text { min, max }
$$

Note that, being $\lambda$ the ratio between the maximum estimated value of the assessment quantity being analyzed and its related limit value, the influence indicator represents the ratio between the relative variation of the output and the relative variation of the modified parameter. Its denominator would be 1 if the modified parameter would increase a $100 \%$ from Pref to Pmax, or -1 if it would decrease a $100 \%$ from Pref to Pmin. Therefore, if the variation of the output is supposed to be linear, an influence indicator of $r \%$ means that the maximum estimated value of the assessment quantity being analyzed increases/decreases an $r \%$ of its related limit value when the modified parameter increases/decreases a $100 \%$. According to this interpretation, 5 different levels were set for the influence of a given parameter: low $(|\operatorname{lnf}|<10 \%)$; moderate $(10 \% \leq|\operatorname{lnf}|<25 \%)$; noticeable $(25 \% \leq|\operatorname{lnf}|<50 \%)$; high $(50 \% \leq|\operatorname{lnf}|<75 \%)$ and very high $(|\operatorname{lnf}| \geq 75 \%)$.

\subsubsection{Table of global influences}

For each evaluation index, the influence indicators obtained for the extreme values, Pmin and Pmax, assigned to the modified parameter, with the same track layout, the same 
speed and the same type of track section were compared to obtain the highest influence. This was computed as the influence indicator with the highest absolute value:

$$
\widehat{\operatorname{Inf}}= \begin{cases}\operatorname{In} f_{\text {min }}, & \text { if }\left|\operatorname{Inf} f_{\text {min }}\right| \geq\left|I n f_{\text {max }}\right| \\ \operatorname{Inf} f_{\text {max }}, & \text { if }\left|I n f_{\text {max }}\right| \geq\left|I n f_{\text {min }}\right|\end{cases}
$$

To further ease the appraisal of the simulation results for each evaluation index, the highest influences were grouped by type of track section (Cv, Tr, St) (see Table 6). They were also grouped by track layout (RS, RM $\circ \mathrm{RL}$ ) and by speed (Vmin, Vref and Vmax). Then, the global influence was calculated as the highest absolute value obtained inside each group.

The global influences were put together in a table (see Table 7), where columns 3-5 show the global influence found for each type of track section: curve, $\mathrm{Cv}$, transition curve, $\mathrm{Tr}$, and straight track, St; columns 6-8 show the global influence found for each track layout: $\mathrm{RS}, \mathrm{RM}$ and RL; and columns 9-11 show the global influence found for each speed category: Vmin, Vref and Vmax. The last column shows the highest global influence obtained in all these categories. This table allows to quickly determine which kind of dynamic behaviour leads to the most critical situations. The least critical results (below $10 \%$ ) were identified with an empty circle, $\bigcirc$, the most critical (over $75 \%$ ) with a full black circle, 0 , and the intermediate ones with partially-filled circles: for influences between $10 \%$ and $25 \%$, for influences between $25 \%$ and $50 \%$, and 0 for influences between $50 \%$ and $75 \%$.

\subsubsection{Numerical example}

As an example, for the variations performed on the friction coefficient, it takes the values: $P \min =0.1 ; \operatorname{Pref}=0.4 ; P \max =0.6$. For the evaluation index $S A F-1$, the corresponding $\lambda$ ratios obtained for the simulations performed for $R S$ track layout at Vmin in curved track sections, $\mathrm{Cv}$, are: $\lambda_{\min }=26.8 \% ; \lambda_{\text {ref }}=29.2 \% ; \lambda_{\max }=36.2 \%$. From these values, the related influence indicators result in: $\operatorname{Inf}_{\min }=-2.4 \% /(-0.75)=3.2 \%$ and $\operatorname{Inf}_{\max }=7 \% / 0.5=14.0 \%$, the highest influence being $14.0 \%$. This value is collected in the top-left cells of the three blocks of Table 6 .

Table 6 shows the highest influences computed for the evaluation index SAF-1 when modifying the friction coefficient. The left, central and right blocks respectively show the highest influences grouped by type of track section (Cv, Tr, St), by track layout (RS, RM, $\mathrm{RL}$ ) and by speed (Vmin, Vref, Vmax). The value with highest absolute value of each column was highlighted in bold.

\begin{tabular}{|c|c|c|c|c|c|c|c|c|c|c|c|}
\hline & (Cv) & (Tr) & (St) & & RS & RM & RL & & Vmin & Vref & $V \max$ \\
\hline RS-Vmin & 14.0 & 6.5 & 2.0 & Cv-Vmin & 14.0 & 15.9 & 20.5 & RS-CV & 14 & 11.8 & 8.6 \\
\hline RS-Vref & 11.8 & -12.2 & 2.0 & Cv-Vref & 11.8 & 13.6 & 18.7 & RS-Tr & 6.5 & -12.2 & -18.6 \\
\hline $\mathrm{RS}-\mathrm{V} \max$ & 8.6 & -18.6 & 2.0 & CV-Vmax & 8.6 & 16.6 & 270.2 & RS-St & 2 & 2 & 2 \\
\hline $\mathrm{RM}-\mathrm{Vmin}_{\mathrm{min}}$ & 15.9 & 15.6 & 2.1 & Tr-Vmin & 6.5 & 15.6 & 20.7 & RM-Cv & 15.9 & 13.6 & 16.6 \\
\hline RM-Vref & 13.6 & 15.4 & 2.1 & Tr-Vref & -12.2 & 15.4 & 19.9 & RM-Tr & 15.6 & 15.4 & 22.6 \\
\hline RM-Vmax & 16.6 & 22.6 & 2.7 & Tr-Vmax & -18.6 & 22.6 & 537.0 & RM-St & 2.1 & 2.1 & 2.7 \\
\hline $\mathrm{RL}-\mathrm{V}_{\min }$ & 20.5 & 20.7 & 4.3 & St-Vmin & 2.0 & 2.1 & 4.3 & RL-CV & 20.5 & 18.7 & 270.2 \\
\hline RL-Vref & 18.7 & 19.9 & 6.8 & St-Vref & 2.0 & 2.1 & 6.8 & RL-Tr & 20.7 & 19.9 & 537 \\
\hline RL-Vmax & 270.2 & 537.0 & 521.0 & St-Vmax & 2.0 & 2.7 & 521.0 & RL-St & 4.3 & 6.8 & 521 \\
\hline
\end{tabular}

Finally, Table 7 shows the global influence for the variations in the friction coefficient, $f$, for the five safety criteria. Note that the values gathered in the second row are the highlighted values of Table 6 rounded to the nearest integer. 


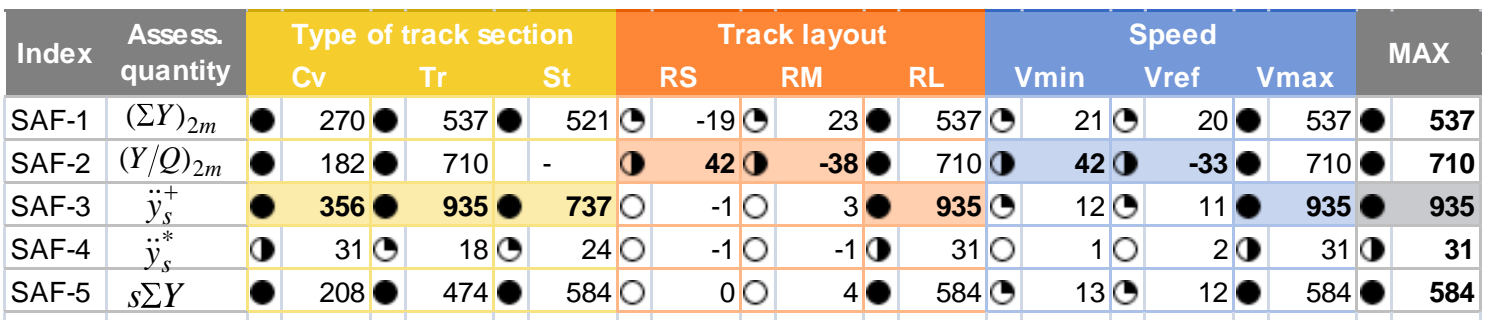

Variation range $(P 10 ; P 90)$ from $25 \%$ to $150 \%$ of the reference value (P50).

Legend: $\quad O$ Low (Influence $<10 \%)$; Moderate $(10 \% \leq$ Influence $<25 \%) \quad$ Noticeable $(25 \% \leq$ Influence $<50 \%$

- High $(50 \% \leq$ Influence $<75 \%)$; Very high (Influence $\geq 75 \%$ ).

Table 7 Table of global influences: Friction coefficient

Whether the global influences were classified by type of track section, by track layout or by speed, the highest global influence found is always the same (935\% in this example). In this way, it is easy to identify which is the type of track section, the track layout or even the vehicle speed that show the highest global influence. On the other hand, by looking at the values in the last column, it is also possible to identify which evaluation index provides the highest global influence.

In the following paragraphs, the global influences obtained when comparing the results of the different simulations performed is presented. Hereafter, for simplicity, global influences will be called just influences.

\subsection{INFLUENCE OF THE TRACK QUALITY}

The following tables show the influence obtained when analyzing the following elastic properties of the track:

- $\quad$ Track quality, QN (Table 8)

\begin{tabular}{|c|c|c|c|c|c|c|c|c|c|c|c|c|c|}
\hline \multirow{2}{*}{ Index } & \multirow{2}{*}{$\begin{array}{l}\text { Assess. } \\
\text { quantity }\end{array}$} & \multicolumn{4}{|c|}{ Type of track section } & \multicolumn{4}{|c|}{ Track layout } & \multicolumn{3}{|c|}{ Speed } & \multirow{2}{*}{ MAX } \\
\hline & & \multicolumn{2}{|r|}{ Cv } & Tr & St & \multicolumn{2}{|r|}{ RS } & RM & $\mathbf{R L}$ & Vmin & Vref & Vmax & \\
\hline AF-1 & $(\Sigma Y)_{2 m}$ & $\boldsymbol{\bullet}$ & 55 & 242 & 299 & ( & $16 \odot$ & $23 \bullet$ & 2990 & 320 & 40 & 299 & 299 \\
\hline$A F-2$ & $(Y / Q)_{2 m}$ & ) & 500 & 262 & - & 0 & 30 & 120 & $262-$ & $12 €$ & 130 & 262 & 262 \\
\hline SAF-3 & $\ddot{y}_{s}^{+}$ & - & $93 \bullet$ & $456 \bigcirc$ & 440 & () & 120 & $35 \bigcirc$ & 4560 & 46 & 570 & 456 & 456 \\
\hline SAF-4 & $\ddot{y}_{s}^{*}$ & - & 170 & $33 \oplus$ & 40 & () & 140 & 180 & 400 & $20 €$ & $20 \%$ & 400 & 40 \\
\hline$A F-5$ & $s \sum Y$ & - & $95 \bigcirc$ & 369 & 519 & 0 & 20 & 20 & 5190 & $21 c$ & 230 & 519 & 519 \\
\hline \multirow{2}{*}{ Index } & \multirow{2}{*}{\multicolumn{2}{|c|}{$\begin{array}{l}\text { Assess. } \\
\text { quantity }\end{array}$}} & \multicolumn{4}{|c|}{ Type of track section } & \multicolumn{3}{|c|}{ Track layout } & \multicolumn{3}{|c|}{ Speed } & \multirow{2}{*}{ MAX } \\
\hline & & & Cv & $\operatorname{Tr}$ & St & & RS & RM & RL & Vmin & Vref & Vmax & \\
\hline AT-1 & $Q$ & 0 & 70 & $11 \bullet$ & 61 & & 60 & 50 & 610 & 50 & 70 & $61 \bullet$ & 61 \\
\hline AT-2 & $Y_{q s t}$ & 0 & 3 & - & - & 0 & 30 & 3 & 0 & 30 & 30 & 30 & D \\
\hline EAT-3 & $Q_{q s t}$ & 0 & 0 & - & - & 0 & 00 & 0 & 0 & 00 & 00 & 00 & $D$ \\
\hline \multirow{2}{*}{ Index } & \multirow{2}{*}{\multicolumn{2}{|c|}{$\begin{array}{l}\text { Assess. } \\
\text { quantity }\end{array}$}} & \multicolumn{3}{|c|}{ Type of track section } & \multicolumn{4}{|c|}{ Track layout } & \multicolumn{3}{|c|}{ Speed } & \multirow{2}{*}{ MAX } \\
\hline & & & Cv & $\operatorname{Tr}$ & St & & RS & $\mathbf{R M}$ & RL & Vmin & Vref & $V \max$ & \\
\hline COM-1 & $\ddot{y}_{q}^{*}$ & () & $25 \bullet$ & $71 \bullet$ & 56 & & 140 & $18 \bullet$ & 710 & 210 & $26 \bullet$ & $71 \bullet$ & 71 \\
\hline COM-2 & & ) & 270 & 260 & 33 & & 190 & 330 & 190 & 250 & 310 & 330 & 33 \\
\hline COM-3 & $s \ddot{y}_{q}^{*}$ & $\bullet$ & 610 & $176 \bigcirc$ & 139 & 1 & 340 & 390 & 1760 & 490 & 540 & 1760 & 176 \\
\hline COM-4 & $s \ddot{z}_{q}^{*}$ & $\boldsymbol{\bullet}$ & 520 & $49 \bullet$ & 61 & & 340 & 610 & 360 & 44 & 570 & $61 \bullet$ & 61 \\
\hline COM-5 & $\ddot{y}_{q s t}^{*}$ & 0 & 1 & - & - & 0 & 00 & 00 & 10 & 10 & 10 & 10 & D \\
\hline Variatior & nge $(F$ & 10,1 & P90)trom & $0 \%$ to & $126 \%$ & & the referen & nce value & (P50). & & & & \\
\hline Legend: & & OL & Low (Influen & cee < $10 \%$ ); & & () & Moderate (1 & $0 \% \leq$ Influen & nce $<25 \%$ ) & (1) $\mathrm{N}$ & Voticeable (25 & $5 \% \leq \operatorname{lnfluen}$ & nce $<50 \%$ \\
\hline & & $\boldsymbol{\bullet}$ & High $(50 \% \leq$ & $\leq$ Influence & $<75 \%)$ & - & Very high (In & nfluence $\geq 75$ & & & & & \\
\hline
\end{tabular}

TABLE 8 GLOBAL INFLUENCE OF RESULTS: TRACK QUALITY

From these results, it can be concluded that: 
- QN shows very high influence for safety and ride quality studies. For track fatigue studies, it shows high influence for RL track layouts at Vmax, showing low influence in any other condition.

\subsection{INFLUENCE OF THE PROPERTIES OF THE WHEEL-RAIL CONTACT}

The following tables show the influence obtained when analyzing the following properties of the wheel-rail contact:

- Wheel-rail friction coefficient, $f($ Table 9)

- Equivalent conicity with new wheel profiles, wpn (Table 10)

- Equivalent conicity with worn wheel profiles, wpu (Table 11)

\begin{tabular}{|c|c|c|c|c|c|c|c|c|c|c|c|c|c|}
\hline \multirow{2}{*}{ Index } & \multirow{2}{*}{$\begin{array}{l}\text { Assess. } \\
\text { quantity }\end{array}$} & \multicolumn{4}{|c|}{ Type of track section } & \multicolumn{4}{|c|}{ Track layout } & \multicolumn{3}{|c|}{ Speed } & \multirow{2}{*}{ IAX } \\
\hline & & & Cv & $\operatorname{Tr}$ & St & & RS & RM & RL & Vmin & Vref & Vmax & \\
\hline$A F-1$ & $(\Sigma Y)_{2 m}$ & - & 270 & $537 \bullet$ & 521 & $\mathbf{C}$ & $-19 \odot$ & 23 & $537 \odot$ & $21 c$ & 20 & $537 \bullet$ & 537 \\
\hline$A F-2$ & $(Y / Q)_{2 m}$ & 0 & 1820 & 710 & - & ) & 420 & $-38 \bigcirc$ & 7100 & 420 & -330 & 710 & 710 \\
\hline$A F-3$ & $\ddot{y}_{s}^{+}$ & O & $356 \bigcirc$ & $935 \bigcirc$ & 737 & 0 & -10 & 30 & 935 & $12 c$ & 110 & 9350 & 935 \\
\hline AF-4 & $\ddot{y}_{s}^{*}$ & () & 310 & 180 & 24 & 0 & -10 & -10 & 310 & 10 & 20 & 310 & 31 \\
\hline AF-5 & $s \Sigma Y$ & - & 208 & $474 \bullet$ & 584 & 0 & 00 & 40 & $584 \odot$ & $13 c$ & 12 & 584 & 584 \\
\hline \multirow{2}{*}{ Index } & \multirow{2}{*}{\multicolumn{2}{|c|}{$\begin{array}{l}\text { Assess. } \\
\text { quantity }\end{array}$}} & \multicolumn{3}{|c|}{ Type of track section } & \multicolumn{4}{|c|}{ Track layout } & \multicolumn{3}{|c|}{ Speed } & \multirow{2}{*}{ MAX } \\
\hline & & \multicolumn{2}{|r|}{$\mathrm{Cv}$} & $\operatorname{Tr}$ & St & & RS & RM & RL & Vmin & Vref & Vmax & \\
\hline AT-1 & $Q$ & () & 320 & 115 & 158 & 0 & -50 & 40 & 1580 & -50 & -50 & 158 & 158 \\
\hline =AT-2 & $Y_{q s t}$ & () & 17 & - & - & C) & 170 & -9 & C) & $17 C$ & $14 \div$ & $11 \odot$ & 17 \\
\hline AT-3 & $Q_{q s t}$ & 0 & -2 & - & - & 0 & -20 & 2 & 0 & -20 & 20 & -20 & -2 \\
\hline \multirow{2}{*}{ Index } & \multirow{2}{*}{\multicolumn{2}{|c|}{$\begin{array}{l}\text { Assess. } \\
\text { quantity }\end{array}$}} & \multicolumn{3}{|c|}{ Type of track section } & \multicolumn{4}{|c|}{ Track layout } & \multicolumn{3}{|c|}{ Speed } & \multirow{2}{*}{ MAX } \\
\hline & & & Cv & $\operatorname{Tr}$ & St & & RS & RM & RL & Vmin & Yrof & Vmax & \\
\hline COM-1 & $\ddot{y}_{q}^{*}$ & $\boldsymbol{\bullet}$ & 60 & 100 & 79 & & -10 & 10 & 1000 & 10 & 20 & 100 & 100 \\
\hline COM-2 & & 0 & 10 & 00 & 0 & 0 & 00 & 00 & 10 & 00 & 00 & 10 & 1 \\
\hline COM-3 & $s \ddot{y}_{q}^{*}$ & 0 & 1920 & 308 & 276 & 0 & -30 & 30 & 3080 & 20 & 50 & 308 & 308 \\
\hline COM-4 & $s \ddot{z}_{q}^{*}$ & 0 & 00 & 00 & 0 & 0 & 00 & 00 & 00 & 00 & 00 & 00 & 0 \\
\hline COM-5 & $\ddot{y}_{q s t}^{*}$ & 0 & -2 & - & - & 0 & 00 & 00 & -20 & 00 & 00 & -20 & -2 \\
\hline \multicolumn{4}{|c|}{ Variation range (P10; P90)from } & $25 \%$ to & $150 \%$ & \multicolumn{4}{|c|}{ of the reference value (P50). } & & & & \\
\hline \multirow{2}{*}{\multicolumn{2}{|c|}{ Legend: }} & \multicolumn{4}{|c|}{ Low (Influence < 10\%); } & () 1 & Moderate (1 & $0 \% \leq$ Influen & nce $<25 \%$ ) & (1) $\mathrm{N}$ & Voticeable $(25$ & $5 \% \leq \operatorname{lnfll}$ & $50 \%$ \\
\hline & & $\boldsymbol{\theta}$ & High $(50 \%$ & $\leq$ Influence $<$ & < $75 \%)$ & & Very high (In & nfluence $\geq 75$ & $75 \%)$. & & & & \\
\hline
\end{tabular}

TABLE 9 GLOBAL INFLUENCE OF RESULTS: WHEEL-RAIL FRICTION COEFFICIENT 


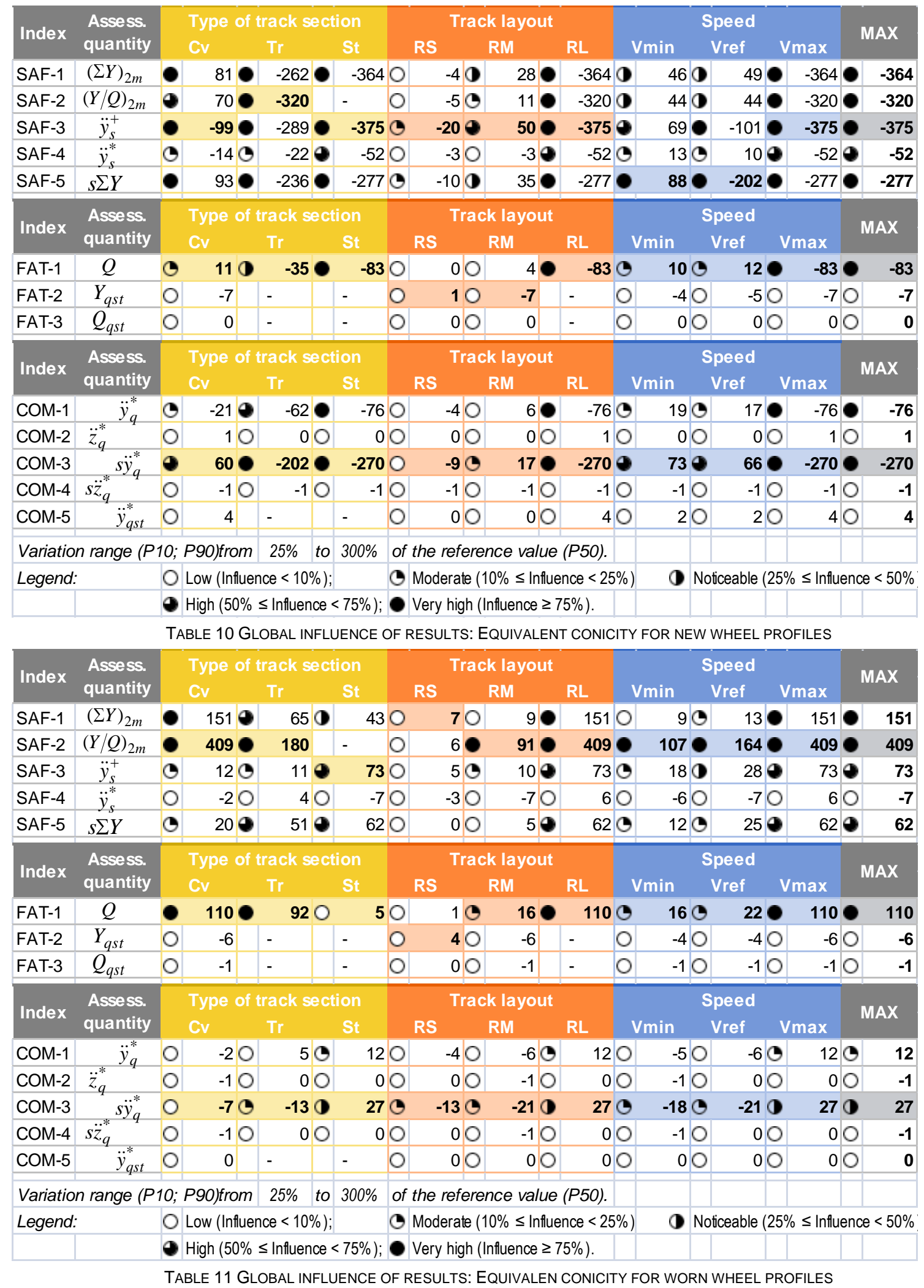

From these results it can be concluded that:

- f shows very high influence for any study. Nevertheless, it can show low influence under certain conditions: for ride quality studies, with RS and RM track layouts at any 
speed or either for speeds lower than Vmax for any track layout; and for track fatigue studies with RM track layout at any speed.

- wpn shows very high influence for any study. Nevertheless, for track fatigue studies it shows low influence with RS or RM track layouts at any speed. In addition, for ride quality studies, it also shows low influence with RS track layout at any speed.

- wpu shows very high influence for safety and track fatigue studies and noticeable influence for ride quality studies. Nevertheless, for safety and track fatigue studies it shows low influence with RS track layout at any speed.

\subsection{FURTHER COMMENTS}

It should be pointed out that the friction coefficient turns out to affect the index SAF-3, which is related to the lateral acceleration of the bogie frame, the most, in $\mathrm{RL}$ track layouts at Vmax (see Table 9). However, intuition would lead to imagine that on large radius curves the wheel creepages would be such that the friction coefficient would play a minor role. To understand this phenomenon, attention should be paid to index SAF-5, which is related to vehicle stability. This index was also over $100 \%$ for $\mathrm{RL}$ track layouts at Vmax, thus indicating that the vehicle become unstable under such conditions, with the wheelsets exhibiting continuous hunting movements, so conditioning the high influences found for other assessment indexes or output quantities, as the lateral acceleration of the bogie frame. In fact, the friction coefficient shows just moderate or noticeable sensitivity on the lateral acceleration of the bogie frame for any other track layout or vehicle speed.

\section{COMPARISON OF RESULTS OF THE SENSITIVITY ANALYSIS}

In this paragraph, the results obtained in the sensitivity analysis are compared. The conclusions obtained from this analysis are also presented here. To have a more comprehensive view, results are grouped into two different categories: track quality and properties of the wheel-rail contact.

Within each group, the results were gathered in the same table, showing the characteristics of the most critical scenarios found when analyzing the influence of each parameter.

\subsection{INFLUENCE OF THE TRACK QUALITY}

Table 12 summarizes the characteristics of the most critical scenarios found when analyzing the influence of the track quality, QN.

\begin{tabular}{|c|c|c|}
\hline & & QN \\
\hline \multirow[t]{5}{*}{ Safety: } & & \\
\hline & Index: & SAF-5, $\mathbf{s} \boldsymbol{\Sigma} \mathbf{Y}$ \\
\hline & Layout: & \\
\hline & Speed: & Vmax \\
\hline & Influence: & (519\%) \\
\hline \multicolumn{3}{|l|}{ Track fatigue: } \\
\hline & Index: & FAT-1, Q \\
\hline & Layout: & \\
\hline & Speed: & Vmax \\
\hline & Influence: & (61\%) \\
\hline \multicolumn{3}{|l|}{ Ride quality: } \\
\hline & Index: & $\mathrm{COM}-3, s \ddot{y}_{q}^{*}$ \\
\hline & Layout: & $\mathrm{RL}$ \\
\hline & Speed: & Vmax \\
\hline & Influence: & (176\%) \\
\hline
\end{tabular}


Influence (I): $\bigcirc$ Low (I<10\%); Moderate (10\% $\leq 1<25 \%) ; \quad$ Noticeable $(25 \% \leq 1<50 \%) ; \quad$ High $(50 \% \leq 1<75 \%)$;

TABLE 12 SUMMARY TABLE: TRACK QUALITY

As can be seen, QN shows very high influence for safety and ride quality studies and high influence for track fatigue studies, the highest influence being found when running on the $\mathrm{RL}$ track layout at Vmax.

\subsection{INFLUENCE OF THE PROPERTIES OF THE WHEEL-RAIL CONTACT}

Table 13 summarizes the characteristics of the most critical scenarios found when analyzing the influence of the properties of the wheel-rail contact.

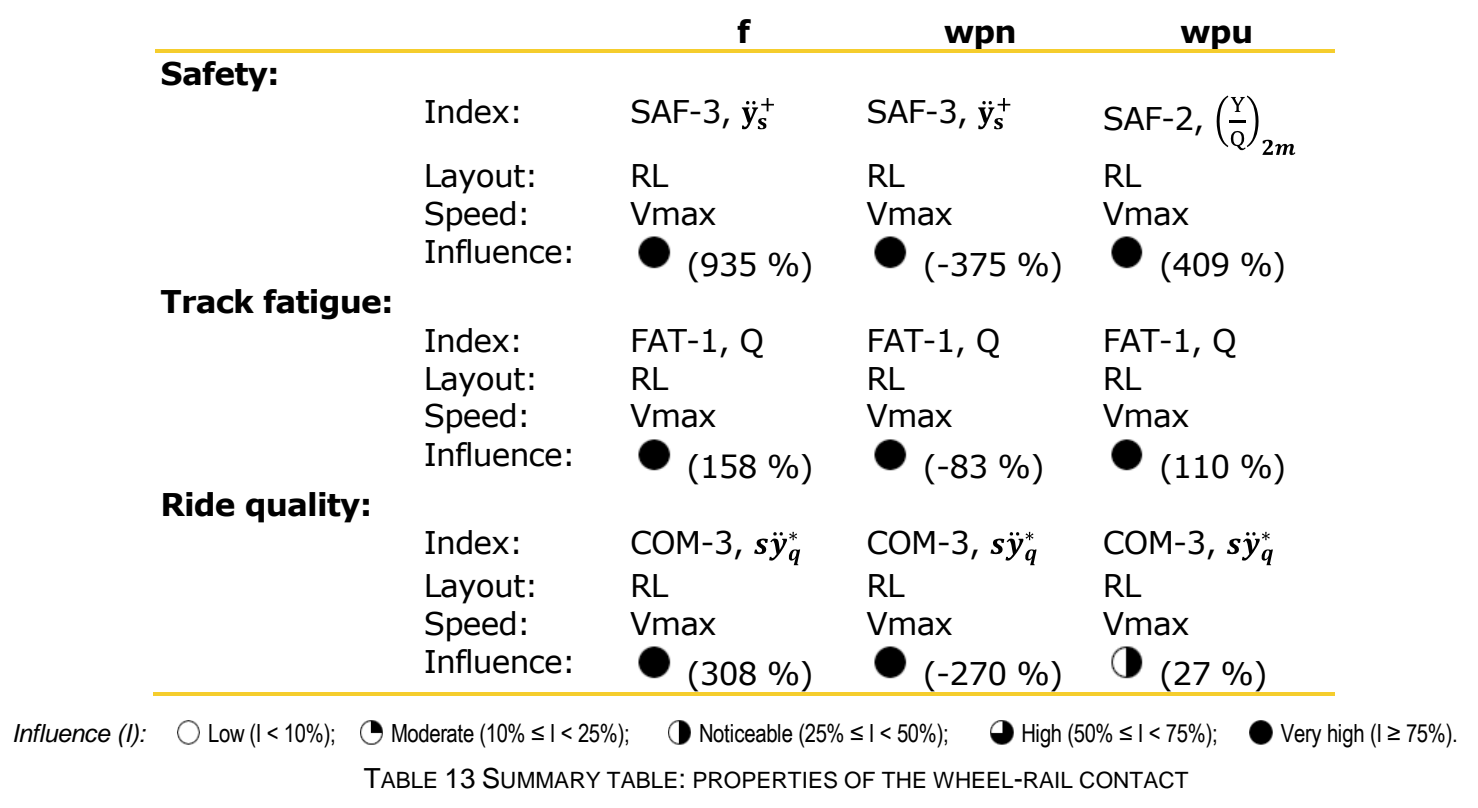

In view of these results, the three parameters show a very high influence, especially for safety studies, the highest influences being found when running on the $R L$ track layout at Vmax for any study.

\subsection{ORDERING THE PARAMETERS ANALYZED BY INCREASING INFLUENCE}

In accordance with the previous results it could be said that all the parameters analyzed show very high influence, being $f$ the most sensitive one. Of the remaining parameters, QN shows higher influence than the others for safety studies, wpu for track fatigue studies and wpn for ride quality studies.

It was also intended to group the properties of the wheel-rail contact considering the operating conditions under which their value could be estimated with a lesser degree of accuracy for future simulations, without significantly affecting the simulation results. However, this was not possible, as all the parameters analyzed show low influence just for some particular combinations of study, track layout and speed, and no general rule could be found.

Therefore, it is recommended to undertake any future simulation job with measured track irregularities, measured wheel profiles and normative values of wheel-rail friction coefficient. 


\section{CONCLUDING REMARKS}

In this work, the influence of the track quality and that of some parameters of the wheelrail contact were analyzed to assess their impact on the vehicle's dynamic behaviour. To this end, a reference vehicle model was used and, as a whole, 4 parameters were modified: track quality, wheel-rail friction coefficient and equivalent conicity for both new and worn wheel profiles.

Due to the number of uncertain parameters and external conditions (vehicle speed and track layout) to be considered, a simple approach, consisting in modifying the input parameters one at a time, was chosen to perform this study. This way, the study was focused on passenger vehicles, and the input parameters were modified one at a time, with just three values in each variation, so assuming that the output quantities are smooth functions of the input parameters. Therefore, as previously stated, the conclusions that can be drawn are also limited from a quantitative point of view, but they can provide a qualitative idea about which influence quantities need to be addressed with particular care when performing simulations addressing a specific problem.

To undertake the study, a reference value was assigned to each parameter and two additional values were assigned to each parameter. In particular, three different track classes were considered. This way, apart from the reference track quality, QN1, two other track classes were used: QN0, which is an ideal track with no defects, and QN2, with higher level of track defects than QN1. In the same way, in order to consider different values of the equivalent conicity, several wheel profiles were also included in the simulation models. These wheel profiles were chosen so that the equivalent conicities obtained for lateral displacements of the wheels of $3 \mathrm{~mm}$ would substantially differ from one wheel profile to another. For each wheel, two wear states were also considered, one for a new wheel and another one for a reprofiled wheel.

As a whole, 72 dynamic simulations were performed. After processing the results of the simulations, it was intended to group the properties of the wheel-rail contact considering the operating conditions under which their value could be estimated with a lesser degree of accuracy for future simulations, without significantly affecting the simulation results. However, this was not possible, as all the parameters analyzed show low influence just for some particular combinations of study, track layout and speed, and no general rule could be found.

It was also concluded that all the parameters considered show very high influence, though the friction coefficient shows the highest influence. So, it is recommended to undertake any future simulation job with measured track irregularities, measured wheel profiles and normative values of wheel-rail friction coefficient.

These results could be useful when not all the data required to undertake a future simulation job are initially known, and there are no possibilities of testing, as sometimes happens when dealing with derailment reconstructions. In such situations, the previous results could help to decide whether to accept or not any possible request to undertake a dynamic analysis for a vehicle or a track with some unknown parameters.

Further development of the work proposed here might consist in varying the parameters found to be most important in smaller steps, in extending the number of both new and worn wheel profiles used or, even further, in undertaking a probabilistic approach to consider simultaneous variations of the uncertain input parameters.

\section{REFERENCES}

1. Suarez, Berta. Metodología Analitica para el Estudio de Sensibilidades Aplicado a Modelos de Simulación Dinámica de Vehículos Ferroviarios, desde el Punto de Vista 
de la Seguridad, la Fatiga de Vía y la Calidad de Marcha. Madrid : Sección de Publicaciones de la Escuela Técnica Superior de Ingenieros Industriales, 2010. 978-84-693-2329-8.

2. Suarez, B., Felez, J. and Maroto, J. Sensitivity analysis to assess the impact of the inertial properties of railway vehicle bodies on the vehicle's dynamic behaviour. Vehicle System Dynamics. under review.

3. Suarez, B., Mera, J.M. and Muneta, M.L. Sensitivity analysis to assess the impact of the elastic properties of railway vehicle suspensions on the vehicle's dynamic behaviour. in preparation.

4. Mazzola, Laura and Bruni, Stefano. Effect of suspension parameter uncertainty on the dynamic behaviour of railway vehicles. Applied Mechanics and Materials. 2012, Vol. 104, pp. 177-185.

5. Sandu, Adrian, Sandu, Corina and Ahmadian, Mehdi. Modeling multibody systems with uncertainties. Part I: Theoretical and computational aspects. Multibody System Dynamics. 2006, Vol. 15, pp. 373-395.

6. Suarez, B., Sanz, J.D. and Felez, J. Hierarchical classification of railway vehicles by the application of taxonomic analysis techniques. Probabilistic Engineering Mechanics. under review.

7. Suarez, B., Felez, J. and Sanz, J.D. Proposal of a Reference Model for Dynamic Sensitivity Analysis of Long-Distance Railway Passenger Cars. Probabilistic Engineering Mechanics. under review.

8. UIC. UIC-518, Testing and Approval of Railway Vehicles from the Point of View of their Dynamic Behaviour - Safety - Track Fatigue - Ride Quality. 2003.

9. CEN. EN 14363, Aplicaciones Ferroviarias - Ensayos para la Aceptación del Comportamiento Dinámico de los Vehículos Ferroviarios - Ensayos en Línea y en Parada. 2007.

10. Orlova, Anna and Boronenko, Yuri. The Anatomy of Railway Vehicle Running Gear. [ed.] Simon Iwnicki. Handbook of Railway Vehicle Dynamics. Boca Raton : CRC Press, 2006, 3, pp. 1-552.

11. Dynamic Simulations of Talgo Track-Inspection Trainset. Garcia, Emilio and Chiva, Jesús. Berchtesgaden (Germany) : s.n., 2001. 16th European ADAMS User Conference.

12. Polach, O. On Non-Linear Methods of Bogie Stability Assessment using Computer Simulations. Journal of Rail and Rapid Transit. 2006, Vol. 220, pp. 13-27.

13. Suda, Yoshihiro, Miyamoto, Takefumi and Katoh, Norihiko. Active Controlled Rail Vehicles for Improved Curving Performance and Response to Track Irregularity. Vehicle System Dynamics Supplement. 2001, Vol. 35, pp. 23-40.

14. Cheli, F., et al. Effects of Track Geometrical Defects on Running Safety of Tramcar Vehicles. Vehicle System Dynamics Supplement. 2006, Vol. 44, pp. 302312.

15. Demiridis, N. and Pyrgidis, C. Speed as a Stand-Alone Indicator of the Quality of the Railway Track. Journal of Rail and Rapid Transit. 2007, Vol. 221, pp. 419-428.

16. Esveld, C. Modern Railway Track. s.1. : MTR Production, 2001. 90-80032-3-3.

17. Wu, Yean-Seng, Yang, Yeong-Bin and Yau, Jong-Dar. Three-Dimensional Analysis of Train-Rail-Bridge Interaction Problems. Vehicle System Dynamics. 2001, Vol. 36, pp. 1-35.

18. Yang, Y. B., Yau, J. D. and Wu, Y. S. Vehicle-Bridge Interaction Dynamics. Singapore : World Scientific Publishing, 2004. 981-238-847-8.

19. Andersson, C. and Dahlberg, T. Wheel/Rail Impacts at a Railway Turnout Crossing. Journal of Rail and Rapid Transit. 1998, Vol. 212, pp. 123-134. 
20. La Evolución de los Bogies. Nouvion, F. [ed.] Asociación de Investigación del Transporte. Madrid : s.n., 1977. Simposio sobre Dinámica Ferroviaria. pp. 125209.

21. Stiche1, S. On Freight Wagon Dynamics and Track Deterioration. Journal of Rail and Rapid Transit. 1999, Vol. 213, pp. 243-254.

22. Metro de Madrid Rolling Stock Models and Comparative Studies Related to Comfort. González, F. J., et al. [ed.] I. Zobory. Budapest (Hungary) : s.n., 2004.

Proceedings of the 6th International Conference on Railway Bogies and Running Gears. pp. 83-92.

23. Kargarnovin, M. H., et al. Ride Comfort of High-Speed Trains Travelling over Railway Bridges. Vehicle System Dynamics. 2005, Vol. 43, pp. 173-199.

24. Miyamoto, Masayuki and Suda, Yoshihiro. Recent Research and Development on Advanced Technologies of High-Speed Railways in Japan. Vehicle System Dynamics. 2003, Vol. 40, pp. 55-99.

25. Models Development for Applications in Railway Dynamics. Pombo, Joao, et al. Haarlem (The Netherlands), 2000. 5th ADAMS/Rail Users' Conference.

26. Sun, Y. Q. and Cole, C. Comprehensive Wagon-Track Modelling for Simulation of Three-Piece Bogie Suspension Dynamics. Proceedings of the IMechE-Part C: Journal of Mechanical Engineering Science. 2007, Vol. 221, pp. 905-917.

27. Dukkipati, R. V. A Parametric Study of the Lateral Stability of a Rail Bogie on a Roller Rig. Journal of Rail and Rapid Transit. 1999, Vol. 213, pp. 39-47.

28. Dukkipati, Rao V. Lateral Stability Analysis of a Railway Truck on Roller Rig. Mechanism and Machine Theory. 2001, Vol. 36, pp. 189-204.

29. Garg, V. K. and Dukkipati, R. V. Dynamics of Railway Vehicle Systems. s.1. : Academic Press, 1984. 0122759508.

30. Giménez, José Germán. Estabilidad en Dinámica Ferroviaria. II Curso de Especialización en Tecnologías Ferroviarias. Madrid : CITEF, 2001.

31. Lee, Sen-Yung and Cheng, Yung-Chang. Hunting Stability Analysis of HighSpeed Railway Vehicle Trucks on Tangent Tracks. Journal of Sound and Vibration. 2005, Vol. 282, pp. 881-898.

32. Dynamic Analysis of a New Double Deck Passenger Vehicle with Bogie PW200. Lu, Zhenggang and Hecht, Markus. Utrecht (The Netherlands) : s.n., 1999. 4th ADAMS/Rail Users' Conference.

33. Mei, T. X. and Goodall, R. M. Stability Control of Railway Bogies using Absolute Stiffness: Sky-Hook Spring Approach. Vehicle System Dynamics Supplement. 2006, Vol. 44, pp. 83-92.

34. Stability Investigations and Narrow Curving Analysis of a Streetcar Model. Parena, Daniela, et al. Utrecht (The Netherlands) : s.n., 1999. 4th ADAMS/Rail Users' Conference .

35. Modelos de Cálculo de la Dinámica de los Vehículos. Sauvage, G. [ed.] Asociación de Investigación del Transporte. Madrid : s.n., 1977. Simposio sobre Dinámica Ferroviaria. pp. 61-123.

36. Allen, P. D. and Iwnicki, S. D. The Critical Speed of a Railway Vehicle on a Roller Rig. Journal of Rail and Rapid Transit. 2001, Vol. 215, pp. 55-64.

37. Franke, Cornelia. Periodic Motions and Nonlinear Dynamics of a Wheelset Model. International Journal of Bifurcation and Chaos. 1999, Vol. 9, pp. 1983-1994.

38. Dynamic Simulation of a Friction Damped Railway Vehicle. Gugliotta, A., Somà, A. and Mauro, S. R. di. Utrecht : s.n., 1999. 4th ADAMS/Rail Users' Conference.

39. Lorenzo, Michael de. NUCARS Modeling of a Freight Locomotive with Steerable Trucks. Virginia Polytechnic Institute and State University. 1997. Tesis. 
40. Markine, V. L., Shevtsov, I. Y. and Esveld, C. An Inverse Shape Design Method for Railway Wheel Profiles. Structural and Multidisciplinary Optimization. 2007, Vol. 33, pp. 243-253.

41. Polach, O. On Non-Linear Methods of Bogie Stability Assessment using Computer Simulations. Journal of Rail and Rapid Transit. 2006, Vol. 220, pp. 13-27.

42. Stichel, Sebastian. Limit Cycle Behaviour and Chaotic Motions of Two-Axle Freight Wagons with Friction Damping. Multibody System Dynamics. 2002, Vol. 8, pp. 243-255.

43. Wickens, Alan. H. Fundamentals of Rail Vehicle Dynamics: Guidance and Stability. s.1. : Swets \& Zeitlinger, 2003. 90-265-1946-X.

44. Wu, H. Effects of Wheel and Rail Profiles on Vehicle Performance. Vehicle System Dynamics Supplement. 2006, Vol. 44, pp. 541-550.

45. Zboinski, Krzysztof and Dusza, Miroslaw. Analysis and Method of the Analysis of Non-Linear Lateral Stability of Railway Vehicles in Curved Track. Vehicle Sysiem Dynamics Supplement. 2004, Vol. 41, pp. 222-231.

46. Zboinski, K. and Dusza, M. Development of the Method and Analysis for NonLinear Lateral Stability of Railway Vehicles in a Curved Track. Vehicle System Dynamics Supplement. 2006, Vol. 44, pp. 147-157.

47. Dukkipati, Rao.v. Vehicle Dynamics. s.1. : Alpha Science International, Ltd, 2000. 1842650149.

48. Ishida, Hiroaki, et al. Safety Assessment for Flange Climb Derailment of Trains Running at Low Speeds of Sharp Curves. Quarterly Reports or RTRI. 2006, Vol. 47, pp. 65-71.

49. Matsumoto, K., et al. The Optimum Design of an Onboard Friction Control System between Wheel and Rail in a Railway System for Improved Curving Negotiation. Vehicle System Dynamics Supplement. 2006, Vol. 44, pp. 531-540.

50. Nagase, K., Wakabayashi, Y. and Sakahara, H. A Study of the Phenomenon of Wheel Climb Derailment: Results of Basic Experiments using Model Bogies. Journal of Rail and Rapid Transit. 2002, Vol. 216, pp. 237-247.

51. Novales, Margarita. Análisis y Desarrollo de las Adaptaciones Tecnológicas en Infraestructura y Vehículos para la Implantación de un Sistema de Tranvitrén sobre Lineas de Ferrocarriles de Via Estrecha (FEVE). Universidad de A Coruña. 2005. Tesis Doctoral.

52. A New Approach for the Design of Wheel Profile Geometries. Novales, M., Orro, A. and Bugarin, M. R. Montréal (Canada) : s.n., 2006. 7th World Congress on Railway Research.

53. Santamaria, Javier and Vadillo, Ernesto G. Equivalent Conicity and Curve Radius Influence on Dynamical Performance of Unconventional Bogies. Comparison Analysis. Vehicle System Dynamics Supplemeni. 2004, Vol. 41, pp. 133-142.

54. Toma, Elton Edward. A Computer Model of a Train Derailment. Department of Mechanical Engineering, Queen's University. Ontario (Canada) : s.n., 1998. Thesis.

55. Zeng, Jing and Wu, Pingbo. Study on the Wheel/Rail Interaction and Derailment Safety. Wear. 2008, Vol. 265, pp. 1452-1459.

56. Matsumoto, A., et al. Study on Curving Performance of Railway Bogies by Using Full-Scale Stand Test. Vehicle System Dynamics Supplement. 2006, Vol. 44, pp. 862-873.

57. Simson, S. A. and Cole, C. Idealized Steering for Hauling Locomotives. Journal of Rail and Rapid Transit. 2007, Vol. 221, pp. 227-236. 
58. Jönsson, P. A., Andersson, E. and Stichel, S. Influence of Link Suspension Characteristics Variation on Two-Axle Freight Wagon Dynamics. Vehicle System Dynamics Supplement. 2006, Vol. 44, pp. 415-423.

59. Polach, Oldrich, Berg, Mats and Iwnicki, Simon. Simulation. [book auth.] Simon (ed.) Iwnicki. Handbook of Railway Vehicle Dynamics. Boca Raton : CRC, 2006, 12.

60. Iwnicki, Simon. The Manchester benchmark for rail vehicle simulation. Vehicle System Dynamics. 1999, Vol. 31 (Suppl.), pp. 1-48.

61. European Railway Research Institute - ERRI B 176/DT 290. $B$ 176/3 Benchmark Problem: Results and Assessment. Utrecht : s.n., 1993.

62. VOLPE Center. John A. Volpe National Transportation Systems Center. $L D$ Benchmark. [Online] 2005.

http://www.volpe.dot.gov/coi/pis/work/archive/docs/ldbenchmark/report.pdf.

63. Panagin, Romano. La Dinamica del Veicolo Ferroviario. s.1. : Editrice Universitaria Levrotto \& Bella, 1997. 8882180018.

64. Methods for Running Stability Prediction and their Sensitivity to Wheel/Rail Contact Geometry. Polach, Oldrich and Vetter, Adrian. Budapest (Hungary) : s.n., 2004. Proceedings of the 6th International Conference on Railway Bogies and Running Gears. 